\title{
Development of the Methodology of Monitoring Experimental Tumors using Multimodal Optical Conerence Tomography: the Choice of an Optimal Tumor Model
}

D01. $10.17691 / \operatorname{stm} 2015.7 .2 .01$

Received March 27, 2015

M.A. Sirotkina, PhD, Researcher, Laboratory of Individual Chemotherapy of Cancer, Institute of Biomedical Technologies ${ }^{1}$;

N.L. Buyanova, Junior Researcher, Laboratory of Optical Coherence Tomography, Institute of Biomedical Technologies; PhD Student';

T.I. Kalganova, PhD, Junior Researcher, Laboratory of Regenerative Medicine, Institute of Biomedical Technologies';

M.M. Karabut, Junior Researcher, Laboratory of Study of Optical Structure of Biotissue, Institute of Biomedical Technologies'; PhD Student;

V.V. Elagin, Researcher, Laboratory of High Resolution Microscopy and Genetic Technologies, Institute of Biomedical Technologies';

S.S. Kuznetsov, MD, DSc, Professor, Department of Pathological Anatomy';

L.B. Snopova, DSc, Head of the Morphological Department, Central Scientific Research Laboratory';

G.V. Gelikonov, PhD, Researcher, Laboratory of Optical Coherence Tomography, Institute of Biomedical Technologies ${ }^{1}$; Head of the Laboratory of Highly Sensitive Optical Measurements;

V.Yu. Zaitsev, DSc, Senior Researcher, Laboratory of Optical Coherence Tomography, Institute of Biomedical Technologies ${ }^{1}$; Leading Researcher, Department of Geophysical Research ${ }^{3}$; Leading Researcher, Laboratory of Wave Diagnostic Methods of Laboratory and Natural Objects',

L.A. Matveev, PhD, Researcher, Laboratory of Optical Coherence Tomography, Institute of Biomedical Technologies ${ }^{1}$; Researcher, Department of Geophysical Research ${ }^{3}$;

E.V. Zagaynova, MD, DSc, Director of Institute of Biomedical Technologies';

Head of the Department of Biomedicine;

A. Vitkin, PhD M-CCPM, Senior Scientist, Division of Biophysics and Bioimaging,

Ontario Cancer Institute / Princess Margaret Cancer Centre; Professor at the Department of Medical Biophysics4;

N.D. Gladkova, MD, DSc, Professor, Vice Director for Science, Institute of Biomedical Technologies ${ }^{1}$

${ }^{1}$ Nizhny Novgorod State Medical Academy, 10/1 Minin and Pozharsky Square, Nizhny Novgorod, 603005,

Russian Federation;

${ }^{2}$ Lobachevsky State University of Nizhni Novgorod, 23 Prospekt Gagarina, Nizhny Novgorod, 603950,

Russian Federation;

3Institute of Applied Physics, Russian Academy of Sciences, 46 Ul'yanova St., Nizhny Novgorod, 603950,

Russian Federation;

${ }^{4}$ University of Toronto, 610 University Avenue, Toronto, Ontario, M5G 2M9, Canada

The objective of the research was to study the features of transplantation, growth and visualization of experimental tumors of animals, using multimodal optical coherence tomography (OCT) to develop the methodology of evaluation of individual tumor response to anti-cancer therapy.

Materials and Methods. The research was carried out using an experimental high-speed spectral-domain multimodal OCT system developed at the Institute of Applied Physics of the Russian Academy of Sciences (Russia). The technical characteristics of the system are the following: speed of information acquisition, $20,000 \mathrm{~A}$-scans per second; $1.3 \mu \mathrm{m}$ wavelength; frame size, approximately $4 \times 2 \mathrm{~mm}$; lateral resolution, $25 \mu \mathrm{m}$; and depth resolution, $10 \mu \mathrm{m}$. We evaluated cross-polarized (CP) and microangiopathic (MA) OCT images.

For contacts: Sirotkina Marina Alexandrovna, e-mail: sirotkina_m@mail.ru 
We performed an OCT study of the experimental tumor model of colon adenocarcinoma of mice Colo-26 on BALB/c mice (transplanted by suspension of tumor cells culture) inoculated subcutaneously into the thigh, intradermally into auricle, and in a dorsal skinfold window chamber. In the case of a deep subcutaneous location of a nodule, skin flap over the tumor was surgically opened. CP OCT images were compared with histological preparations (stained using hematoxylin and eosine).

Results. It was established that a Colo-26 tumor growing subcutaneously is not suitable with OCT monitoring investigations. Applying of tumor model with opened skin flap made it possible considerably to increase the visualization depth; however, it is not feasible to use this method for everyday OCT monitoring. The tumor grown within a dorsal window chamber is optimal for the visualization of blood vessels by means the OCT. Nevertheless, the inflammation and edema sometimes observed at the tumor site impeded the MA OCT study. Superficial tumors on the auricle are available for OCT investigation throughout their entire depth if the size of nodule does not exceed $1.5 \mathrm{~mm}$. The tumor model on the auricle is convenient for physiological studies of the state of the vessels during the tumor growth.

Conclusions. The optimal tumor model for dynamic multimodal OCT observation is a tumor on the auricle. Unlike a tumor located on the thigh it is characterized by a subcutaneous location of the nodule yet one which still remains accessible for visualization. The tumor evolving in the ear can be studied using dynamics which would be impossible for the tumor with opened skin flap. Tumors in the dorsal skin window can also be used for research, but the monitoring of their growth is limited to those that are no larger than 5-7 mm, as the nodule goes beyond the window due to the decreased elasticity of the skin, typical of these mice.

Key words: experimental tumor model; colon adenocarcinoma Colo-26; optical coherence tomography; OCT; cross-polarized OCT; microangiopathic OCT.

The main trend in modern experimental and clinical oncology is towards the individualization of treatment, i.e., prescription and adaptation of anti-tumor therapy in accordance with the individual biological properties of the tumor and its primary response to treatment. To determine a therapeutic regimen in clinical practice, the oncologist considers a series of prognostic factors: the state/stage of the process, the receptor status of the tumor, the age and sex of the patient, the presence, extent and intensity of concomitant pathology, previous clinical experience of treating similar patients having analogous types of cancer, etc. However, tumors with similar clinical and biological characteristics often react differently in individual cases and can be considerably different in respect of their sensitivity and responses, both to various types of anti-tumor therapy (radiation therapy (RT), chemoradiotherapy (CRT), photodynamic therapy (PDT)) and to the prognosis [1].

Currently, the possibility of predicting how a tumor will respond to treatment is rather limited. Biophotonics methods are actively being used to evaluate changes in biological activity resulting from treatment of the neoplasia. For example, they make it possible quickly, non-invasively and relatively cheaply, to evaluate the oxygenation status of a tumor, which is nowadays considered to be one of the most important factors determining the prognosis of treatment and the effectiveness of therapeutic interventions [2].

Today it is evident that there is an important and unmet necessity for pre-clinical and clinical in vivo visualization methods for determining the early responses of tumors to the treatments being used [3]. Thus, the development of a sensitive tool for the optical visualization of early changes in the tumor tissues subject to cytotoxic treatment is matter of some urgency.

Optical coherence tomography (OCT) is a developing and promising method which can detect the dynamics of the structural and functional changes in tumor tissues in response to therapy $[4,5]$.
The system for multimodal OCT (MM OCT) described in this paper was designed on the basis of previous experience of constructing a variety of OCT systems. The value of MM OCT requires the ability to detect changes of the tumor in response to treatment: of the cellular component (the tumor cells), of the tumor stromata (the connective tissue and extracellular matrix) and of the microvasculature. The responses of the different components of the tumor are not the same but are finally measurable and can be evaluated quantitatively $[6,7]$.

Conducting MM OCT visualization before and after targeted therapy (PDT, RT and CRT) provides new knowledge and offers a step forwards for the individualization of treatment. This is possible because the principal mode of OCT (detection of the backscatter of the probing radiation by the tissues) is directed at the evaluation of a tumor tissue at a scale of $\sim 10 \mu \mathrm{m}$; the polarization mode detects changes in the stroma; evaluation of changes in tumor vessels using such function of OCT as microangiography in dynamics can be considered as a potential criterion for the effectiveness of the therapy.

For the successful application of the MM OCT method in clinical practice, the conduct of experimental research on animal tumor models is a necessary step in developing techniques of MM OCT investigation and the detection of early prognostic signs of the tumor response to the provided treatment. The main requirement to an object of research using the MM OCT method is its superficial localization, i.e., on skin integuments or mucous membranes. While choosing an experimental model, we were guided by the fact that clinical studies into colorectal cancer were being planned. Thus, we selected an experimental mouse model of colon adenocarcinoma Colo-26. According to the scientific literature it is known that the Colo-26 tumor responds to PDT, RT and CRT [8-10].

We were aware of the experience of using OCT for studying tumors on the thigh, on the auricle and in a 
dorsal skinfold window chamber model. Gobin et al. [11] had observed a change in the OCT backscatter signal resulting from nanoparticle accumulation in tumors implanted in the thigh. Due to nanoparticle scattering laser radiation, the visualization depth was considerably increased while the skin above the tumor did not impede the examination. In the study of Song et al. [12] there was used a tumor on the ear for observing tumor nodules after the injection of cells. The tumor growing in window chamber has been used for the visualization of blood vessels [13].

The objective of the research was to study the features of transplantation, growth and visualization of experimental tumors in animals, by using multimodal OCT to develop the methods of evaluation of individual tumor responses to anti-cancer therapy.

Materials and Methods. Research was carried out using an experimental high-speed spectral-domain MM OCT system (Figure 1) developed at the Institute of Applied Physics of the Russian Academy of Sciences (Nizhny Novgorod, Russia).

Technical characteristics of the MM OCT system. The MM OCT system is constructed using the principle of spectral signal reception [14-18] providing a speed of information acquisition of 20,000 A scans per second. To study the object we used a broad band light of the near-IR range $(1.3 \mu \mathrm{m})$ with a power of about $15 \mathrm{~mW}$. The system is equipped with a two-coordinate probe scanning the object across a $4 \times 4 \mathrm{~mm}$ area. Scanning can be performed by arbitrary manner which allows implementation of different modes of information acquisition. The system provides a spatial resolution of $25 \times 25 \mu \mathrm{m}$ transversally and of about $10 \mu \mathrm{m}$ in depth. The system is equipped with a module for cross-polarized reception of the image [19]. Beyond the visualization of OCT images in real-time, the software enables threedimensional image representation and the mapping of the microvasculature, based on an original approach [20]. The physical principle behind this differentiation of the vasculature is based on defining the temporal variability of the complete complex signal in each image element forming a speckle pattern. Where the scattering elements are moving, the phase and amplitude of the complex signal of the speckle pattern changes from one scan to the next considerably faster than does the image of the surrounding tissue and this makes it possible to infer that there is blood flowing in these regions. The processing is based on spatiotemporal filtration of sequentially written, strongly overlapped A-scans with a slow rate of lateral scanning (the so-called M-Mode like OCT mode) [20].

Both cross-polarized images (CP OCT) in the initial and orthogonal polarizations, and microangiopathic OCT images (MA OCT) were evaluated as a part of the optimization of the tumor models.

Experimental tumor models. In our experiment, the tumor used was the Colo-26 undifferentiated adenocarcinoma of mice. The tumor was transplanted by subcutaneous or intradermal injection of a tumor cell suspension culture into BALB/c mice. In the paper, we have compared subcutaneous and intradermal injections into the thigh; intradermal injection into the auricle and the dorsal skinfold window chamber. In all cases the inoculated dose was 200 thousand cells. In the case of the deep subcutaneous location of the tumor transplanted into the thigh, we used an open skin flap technique. The intradermal injection into the ear was performed according to the study [12], and the growth of a tumor in the dorsal skinfold window chamber was modelled according to the scheme described in the work [21].

To verify the tumor structure on OCT images and the localization depth, we conducted a parallel correlation with corresponding histological preparations stained with hematoxylin and eosine using standard techniques.

While working with the animals we followed the Guidelines for Works Involving Experimental Animals [22] and International Guiding Principles for Biomedical Research Involving Animals [23], observed ethical principles established by the European Convention for the Protection of Vertebrate Animals Used for Experimental and Other Scientific Purposes (adopted on 18.03.1986 in Strasbourg and confirmed on 15.06.2006 in Strasbourg). The performance of experimental study on animals is allowed by the Ethical Committee of the Nizhny Novgorod State Medical Academy (Minutes No.14 as of December 10, 2013).
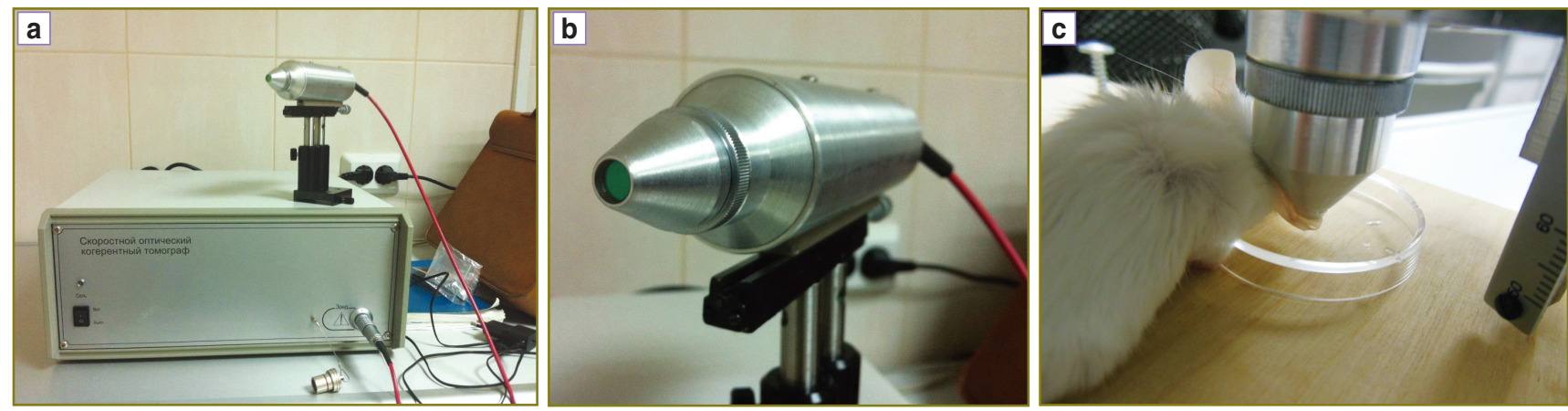

Figure 1. System used for OCT imaging: (a) multimodal OCT device; (b) and (c) OCT probe 

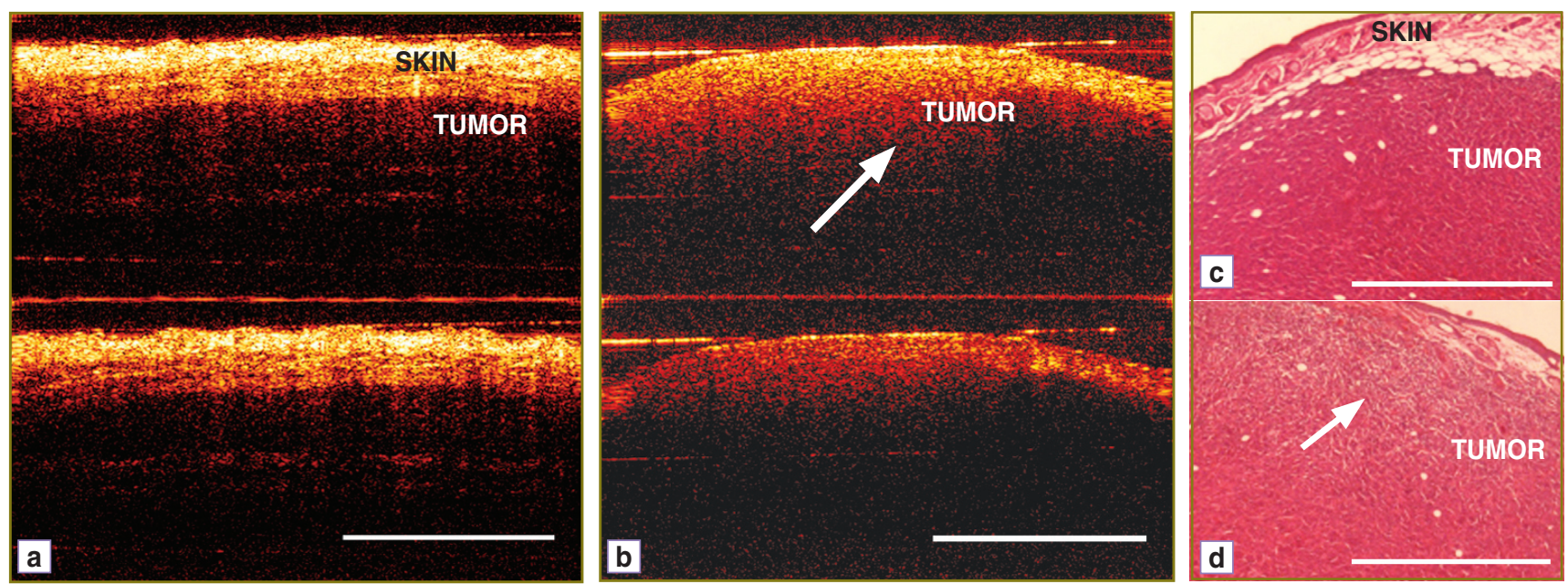

Figure 2. Study of the Colo-26 tumor in the thigh: (a) OCT image of the subcutaneous nodule; (b) OCT image of the intradermal nodule; (c) histological preparation of the subcutaneous nodule (stained with hematoxylin and eosine, frame size $936 \times 702 \mu \mathrm{m}$, scale bar $50 \mu \mathrm{m}$ ); (d) histological preparation of the intradermal nodule (stained with hematoxylin and eosine, frame size $936 \times 702 \mu \mathrm{m}$, scale bar $50 \mu \mathrm{m}$ ). The upper OCT image is the initial polarization, size $2.7 \times 1.7 \mathrm{~mm}$; the lower OCT image is the orthogonal polarization, size $2.7 \times 1.7 \mathrm{~mm}$; scale bar $1 \mathrm{~mm}$. The tumor is indicated by the arrows

Results and Discussion. The morphological analysis of preparations of Colo-26 tumors indicate that their structure is characterized by the tumor cells forming both complexes and strands. The tumors are poor in conjunctive tissue but have a well-developed vasculature (Figure 2 (c), (d)).

With the subcutaneous transplantation of Colo-26 tumors in the area of the thigh the depth of the tumor nodule was 130-200 $\mu \mathrm{m}$ (Figure 2 (c)). The tumor could not be visualized in the OCT images because of the strong scattering by the epidermis and dermis (Figure $2(\mathrm{a})$ ). This hypodermal model is therefore unsuitable for OCT monitoring research.

By using thin needles, $31 \mathrm{G}(0.26 \mathrm{~mm})$, it is possible to provide for superficial injection of the Colo-26 cell culture and the formation of single intradermal tumor nodules of size $3-5 \mathrm{~mm}$ (Figure 2 (b), (d)) by days 5-7. Accordance to the morphological data, the tumor nodules form at a depth $40-100 \mu \mathrm{m}$ from the surface of the epidermis (Figure 2 (d)). However, with the CP OCT image, the depth of signal penetration does not exceed 350-380 $\mu \mathrm{m}$ (Figure 2 (c)). As the optical signal quickly deteriorates as depth increases, especially for the orthogonal polarization, such study of intradermal tumors is also unfeasible.

A greater depth of tumor visualization (up to 800$900 \mu \mathrm{m})$ can be achieved by 'opening' the tumor; in other words, by working using an open flap (Figure 3). The tumor on the OCT image shows no obvious structure but the availability of the signal in both initial and orthogonal polarization makes it possible to use different approaches for quantitative evaluation of the OCT signal [24, 25]. By working with the 'open' tumor, it was possible to avoid skin irritations above the tumor because of hair depilation

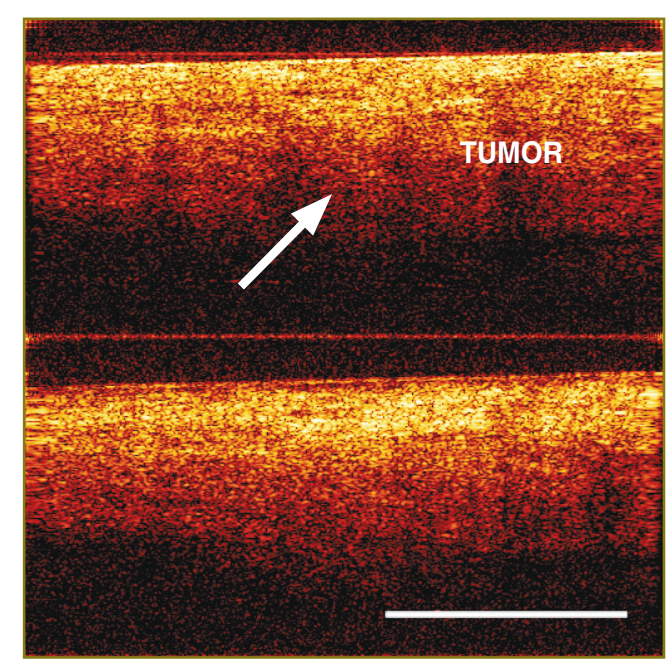

Figure 3. Example of OCT images of Colo-26 'open' tumor using open skin flap technique. The upper OCT image is the initial polarization, size $2.7 \times 1.7 \mathrm{~mm}$; the lower OCT image is the orthogonal polarization, size $2.7 \times 1.7 \mathrm{~mm}$; scale bar $1 \mathrm{~mm}$. The tumor is indicated by the arrow

and (or) skin necrosis as the tumor grows. However, there is a significant disadvantage limiting the application of this technique in that it is not possible to conduct daily monitoring of the state of the tumor nodule.

A promising alternative to the 'open' tumor is modelling of the tumor in a dorsal skinfold chamber window. Here, the tumor nodule remains open while the growth under a coverglass provides the opportunity to perform dynamic observations of the process (Figure 4) from the moment of injection of the tumor cells to the formation of a tumor $5-6 \mathrm{~mm}$ in size. A significant advantage of this model 

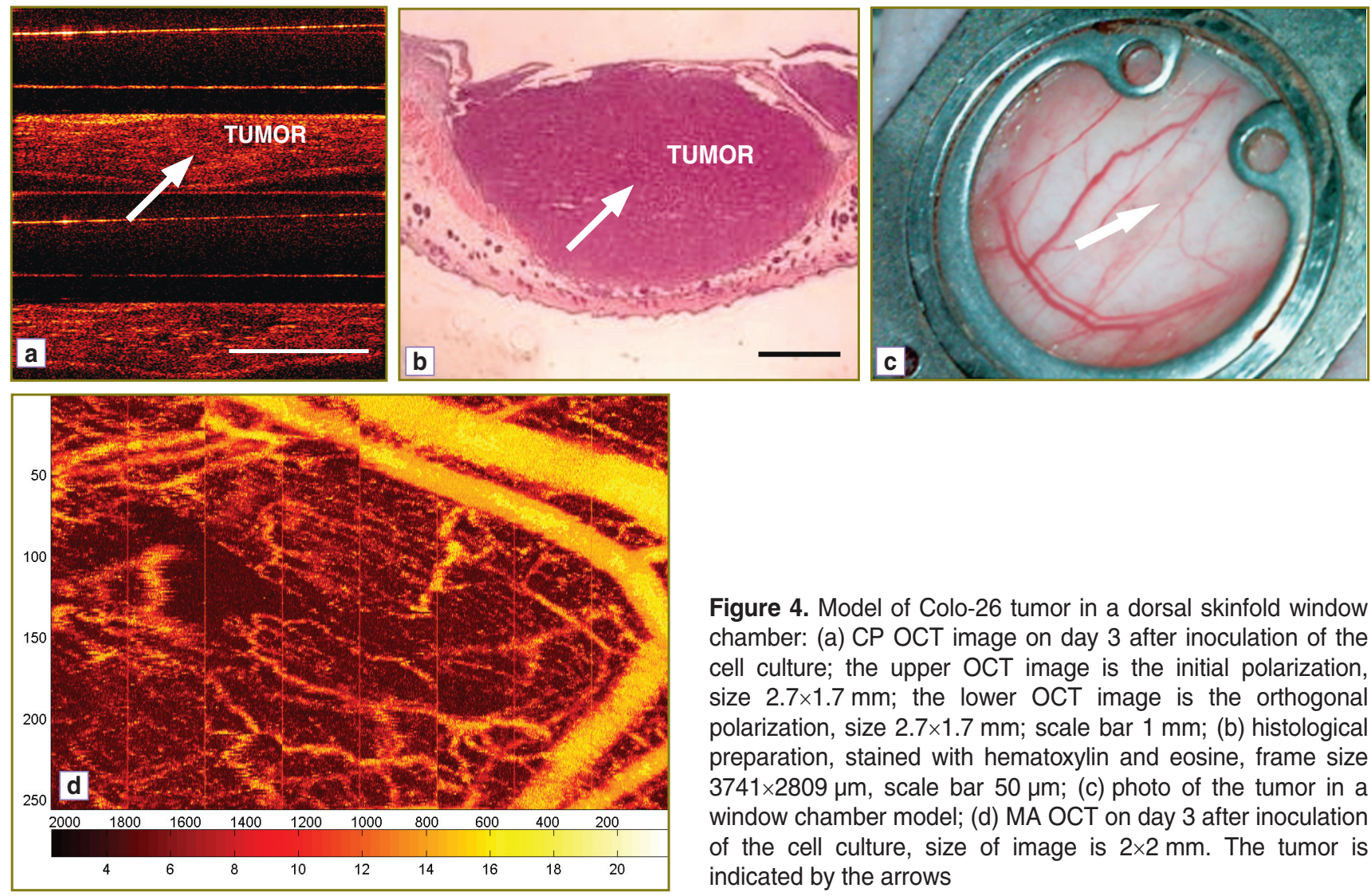

Figure 4. Model of Colo-26 tumor in a dorsal skinfold window chamber: (a) CP OCT image on day 3 after inoculation of the cell culture; the upper OCT image is the initial polarization, size $2.7 \times 1.7 \mathrm{~mm}$; the lower OCT image is the orthogonal polarization, size $2.7 \times 1.7 \mathrm{~mm}$; scale bar $1 \mathrm{~mm}$; (b) histological preparation, stained with hematoxylin and eosine, frame size $3741 \times 2809 \mu \mathrm{m}$, scale bar $50 \mu \mathrm{m}$; (c) photo of the tumor in a window chamber model; (d) MA OCT on day 3 after inoculation of the cell culture, size of image is $2 \times 2 \mathrm{~mm}$. The tumor is indicated by the arrows
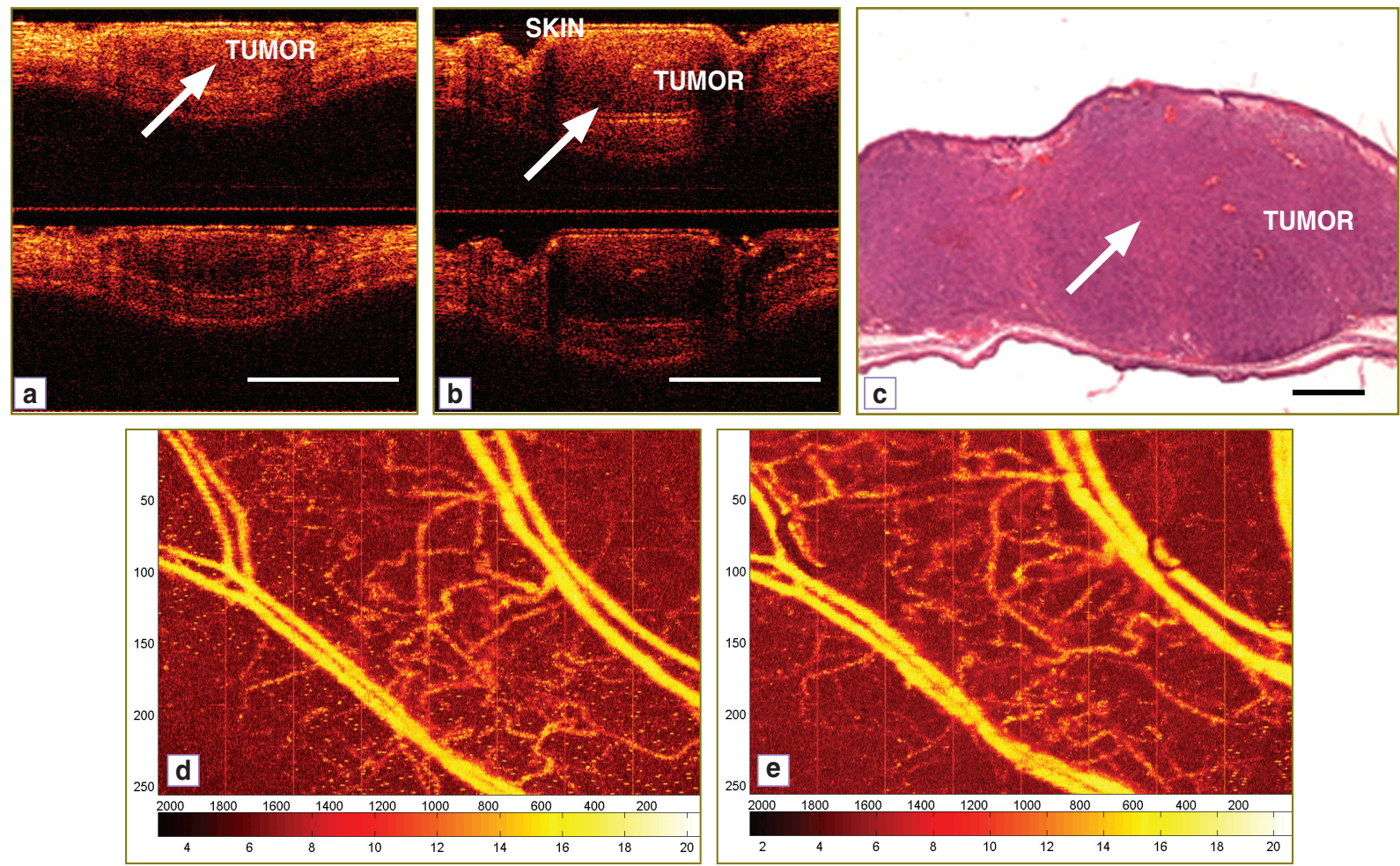

Figure 5. Model of Colo-26 tumor in the ear: (a) and (b) CP OCT images on days 5 and 11 after transplantation; the upper OCT image is the initial polarization, size $2.7 \times 1.7 \mathrm{~mm}$; the lower OCT image is the orthogonal polarization, size $2.7 \times 1.7 \mathrm{~mm}$; scale bar $1 \mathrm{~mm}$; (c) histological preparations, stained with hematoxylin and eosine, frame size $3745 \times 2809 \mu \mathrm{m}$, scale bar $50 \mu \mathrm{m}$; (d) and (e) MA OCT images on days 5 and 11 after transplantation, size of image $2 \times 2 \mathrm{~mm}$ 
is its convenience for the observation of tumor blood vessels and the study of its angiogenesis.

It was established during the experiment that the research duration for the tumor growing within the skinfold window chamber on BALB/c mice is ended once it has reached a size of 5-7 $\mathrm{mm}$. When the nodule grows further, it goes beyond the window chamber because of relatively poor elasticity of the skin of these mice. The tumor growing within the window chamber is a suitable model for vessel visualization, including the use of OCT (Figure 4 (d)). However, sometimes mice used with this model developed inflammation and edema at the tumor site and this interferes with MA OCT research.

Alex Vitkin's group has used athymic nude mice for modeling the tumor in the window chamber to observe MA OCT [26, 27]. The advantage of these mice is the high elasticity of their skin, which allows observation of the tumor growth in within the window chamber much longer. However, the low availability and high price of these mice limit their use in experiments.

The superficial tumor can be modelled by transplantation of the tumor into the surface of the mice auricle. An important advantage of this inoculation is the assured superficial growth of the nodule that is the main requirement for studies using OCT. A peculiarity of this inoculation into the ear is the limitation of injected fluid which can be used, 10-20 $\mu \mathrm{L}$ (in the thigh we were able to inject $50 \mu \mathrm{L}$ of the cell suspension) and this is probably the cause of the relatively low success of this tumor inoculation technique (60-80\% compared with $100 \%$ for the thigh) and the greater spread of nodule occurrence in different species: from 3-4 to 11 days. Despite these features (which can be taken in mind for the planning of experiments correctly), the tumor model on the auricle is optimal for OCT studies. The inoculation into the auricle does not need depilation before the study. Thus the skin above the tumor is not irritated and nothing interferes with OCT visualization.

With the early stages of nodule formation the depth of CP OCT visualization makes it possible to observe the whole tumor nodule both in the initial polarization (copolarized) and orthogonal polarizations (cross-polarized) (Figure $5(\mathrm{a})$ ). The OCT image clearly displays the tissue layers including the cartilage with the perichondrium, the own vessels of the dermis typical of the auricle tissue and confirmed by morphological study (Figure 5 (c)). Development of the tumor nodule is characterized by the erosion of layers specific to the normal structure of the ear and a decrease of optical signal intensity, especially in the orthogonal polarization (Figure $5(b)$ ).

\section{Characteristics of models using the Colo-26 tumor in BALB/c mice}

\begin{tabular}{|c|c|c|c|}
\hline Model characteristic & & Colo-26 tumor localization & \\
\hline Transplantation area & In the thigh & On the auricle & $\begin{array}{l}\text { In a dorsal skinfold window } \\
\text { chamber }\end{array}$ \\
\hline $\begin{array}{l}\text { Superficial location } \\
\text { of the tumor (availability } \\
\text { for OCT research) }\end{array}$ & Usually at late periods of growth & Yes & Yes \\
\hline $\begin{array}{l}\text { Possibility of intradermal } \\
\text { transplantation }\end{array}$ & Injected with thin needles (31 G) & Always intradermal & Yes \\
\hline $\begin{array}{l}\text { Location depth } \\
\text { of the nodule }\end{array}$ & $\begin{array}{l}130-200 \mu \mathrm{m} \text { for the subcutaneous } \\
\text { nodule; } 40-100 \mu \mathrm{m} \text { for the } \\
\text { intradermal nodule }\end{array}$ & $20-65 \mu \mathrm{m}$ & $20-50 \mu \mathrm{m}$ \\
\hline $\begin{array}{l}\text { Characteristics of CP OCT } \\
\text { image }\end{array}$ & $\begin{array}{l}\text { The OCT signal from the tumor } \\
\text { is moderate, but the visualization } \\
\text { depth is no more than } 350 \mu \mathrm{m}\end{array}$ & $\begin{array}{l}\text { The tumor is visible in its entirety } \\
\text { even at late periods of growth up } \\
\text { to up to } 14-17 \text { days from injection; } \\
\text { the OCT signal penetrates } \\
\text { the whole depth of the nodule }\end{array}$ & $\begin{array}{l}\text { The tumor is visible in its entirety } \\
\text { during early periods of growth, } \\
\text { up to the } 7-10^{\text {th }} \text { days; the OCT } \\
\text { signal penetrates the whole depth } \\
\text { of the nodule }\end{array}$ \\
\hline $\begin{array}{l}\text { Skin necrosis above } \\
\text { the tumor }\end{array}$ & $\begin{array}{l}\text { Extensive necrotic areas } \\
\text { are formed }\end{array}$ & $\begin{array}{l}\text { Small necrotic areas may form } \\
\text { in very rare cases, but only } \\
\text { at late periods of growth (more } \\
\text { than } 20 \text { days from the inoculation) }\end{array}$ & No \\
\hline Duration of observation & $\begin{array}{l}\text { Limited by occurrence of necrosis } \\
\text { on days } 7-10\end{array}$ & $\begin{array}{l}\text { In } 80-90 \% \text { of cases, the duration } \\
\text { of observation is up to the } 21 \text { days. } \\
\text { Limited by the occurrence } \\
\text { of necrosis on days } 14-21\end{array}$ & $\begin{array}{l}\text { In } 80-90 \% \text { of cases, the duration } \\
\text { of observation is until the } 7^{\text {th }} \text { day. } \\
\text { Limited by the volume of the tumor. } \\
\text { The tumor should not go beyond the } \\
\text { window chamber }\end{array}$ \\
\hline Inoculation success & $100 \%$ & $60-80 \%$ & $80-100 \%$ \\
\hline $\begin{array}{l}\text { Possibility of CP OCT } \\
\text { and MA OCT monitoring }\end{array}$ & $\begin{array}{l}\text { Limited due to the small } \\
\text { visualization depth }\end{array}$ & Optimal for СР ОСТ, МА ОСТ & $\begin{array}{l}\text { Possible for CP ОСТ, MA ОСТ, } \\
\text { limited when the size of the tumor } \\
\text { reaches } 5-7 \mathrm{~mm}\end{array}$ \\
\hline
\end{tabular}


According to the morphological data, while the tumor nodule grows it can be located either at a certain depth below the epidermis, or close to the epidermis (but without invasive growth into it). The depth of the nodule location is within the range from 20 to $65 \mu \mathrm{m}$ (Figure 5 (c)). Thus it was established that a tumor transplanted into the ear is the most superficial and easy accessible for OCT observation over its entire depth provided that its size does not exceed $1.5 \mathrm{~mm}$ (Figure 5 (a), (b)).

The Table represents comparative data on the model using Colo-26 tumors transplanted into the thigh, the ear or in a dorsal skinfold window chamber of BALB/c mice.

Conclusion. In a comparative study of the features of the transplantation, growth and multimodal OCT visualization of experimental models of Colo-26 tumors in BALB/C mice transplanted into the thigh (including 'open' tumors), the auricle, and in the dorsal skinfold window chamber. It was established that the optimal tumor model for dynamic MM OCT observation is a tumor in the auricle. Unlike the tumor in the thigh this model is characterized by the subcutaneous location of the nodule, while it remains accessible for visualization. The dynamics of the tumor developing in the ear can be studied in ways which are impossible for the 'open' tumor. The tumor in a window chamber can also be used for MM OCT, but monitoring of its growth is limited to a 5-7 mm sized tumor as further growth of the nodule then goes beyond the window chamber, which is restricted by the poor skin elasticity, typical of mice of this line.

Research Funding. This study was performed with financial support in the form of a grant from the Government of the Russian Federation of the Ministry of Education and Science of the Russian Federation (Agreement No.14.V25.31.0015). Studies on improving the methods of MA OCT imaging were conducted with the partial support of grant No.15-42-02513 of the Russian Foundation for Basic Research and an agreement between the Ministry of Education and Science of the Russian Federation and the Lobachevsky State University of Nizhni Novgorod.

Conflicts of Interest. The authors do not have any conflict of interest.

\section{References}

1. Von Minckwitz G., Untch M., Blohmer J.-U., Costa S.D., Eidtmann H., Fasching P.A., Gerber B., Eiermann W., Hilfrich J., Huober J., Jackisch C., Kaufmann M., Konecny G.E., Denkert C., Nekljudova V., Mehta K., Loibl S. Definition and impact of pathologic complete response on prognosis after neoadjuvant chemotherapy in various intrinsic breast cancer subtypes. J Clin Oncol 2012; 30(15): 1796-1804, http://dx.doi. org/10.1200/JCO.2011.38.8595.

2. Vaupel P. Prognostic potential of the pre-therapeutic tumor oxygenation status. Adv Exp Med Biol 2009; 645: 241246, http://dx.doi.org/10.1007/978-0-387-85998-9_36.

3. Yoo S.Y., Kim J.-S., Sung K.W., Jeon T.Y., Choi J.Y., Moon S.H., Son M.H., Lee S.H., Yoo K.H., Koo H.H. The degree of tumor volume reduction during the early phase of induction chemotherapy is an independent prognostic factor in patients with high-risk neuroblastoma. Cancer 2013; 119(3): 656-664, http://dx.doi.org/10.1002/cncr.27775.

4. Standish B.A., Lee K.K.C., Jin X., Mariampillai A., Munce N.R., Wood M.F.G., Wilson B.C., Vitkin I.A., Yang V.X.D. Interstitial Doppler optical coherence tomography as a local tumor necrosis predictor in photodynamic therapy of prostatic carcinoma: an in vivo study. Cancer Res 2008; 68(23): 99879995, http://dx.doi.org/10.1158/0008-5472.CAN-08-1128.

5. Davoudi B., Morrison M., Bizheva K., Yang V.X.D., Dinniwell R., Levin W., Vitkin I.A. Optical coherence tomography platform for microvascular imaging and quantification: initial experience in late oral radiation toxicity patients. $J$ Biomed Opt 2013; 18(7): 076008, http://dx.doi.org/10.1117/1. jbo.18.7.076008.

6. Zaitsev V.Yu., Gelikonov V.M., Matveev L.A., Gelikonov G.V., Matveyev A.L., Shilyagin P.A., Vitkin I.A. Recent trends in multimodal optical coherence tomography. I. Polarization-sensitive OCT and conventional approaches to OCT elastography. Radiophysics and Quantum Electronics 2014; 57(1): 52-66, http://dx.doi.org/10.1007/s11141-0149493-x.

7. Zaitsev V.Yu., Vitkin I.A., Matveev L.A., Gelikonov V.M., Matveyev A.L., Gelikonov G.V. Recent trends in multimodal optical coherence tomography. II. The correlation-stability approach in OCT elastography and methods for visualization of microcirculation. Radiophysics and Quantum Electronics 2014; 57(3): 210-225, http://dx.doi.org/10.1007/s11141-014-9505-x.

8. Daenen L.G.M., Roodhart J.M.L., van Amersfoort M., Dehnad M., Roessingh W., Ulfman L.H., Derksen P.W.B., Voest E.E. Chemotherapy enhances metastasis formation via VEGFR-1-expressing endothelial cells. Cancer Res 2011; 71(22): 6976-6985, http://dx.doi.org/10.1158/0008-5472.can11-0627.

9. Lee W.-C., Chang C.-H., Ho C.-L., Chen L.-C., Wu Y.-H., Chen J.-T., Wang Y.-L., Lee T.-W. Early detection of tumor response by FLT/MicroPET imaging in a C26 Murine colon carcinoma solid tumor animal model. J Biomed Biotechnol 2011, http://dx.doi.org/10.1155/2011/535902.

10. Park $\mathrm{H}$., $\mathrm{Na} \mathrm{K}$. Conjugation of the photosensitizer Chlorin e6 to pluronic F127 for enhanced cellular internalization for photodynamic therapy. Biomaterials 2013; 34(28): 69927000, http://dx.doi.org/10.1016/j.biomaterials.2013.05.070.

11. Gobin A.M., Lee M.H., Halas N.J., James W.D., Drezek R.A., West J.L. Near-infrared resonant nanoshells for combined optical imaging and photothermal cancer therapy. NanoLetters 2007; 7(7): 1929-1934, http://dx.doi.org/10.1021/ nl070610y.

12. Song H.-W., Lee S.-W., Jung M.-H., Kim K.R., Yang S., Won Park J., Jeong M.-S., Jung M.Y., Kim S. Optical monitoring of tumors in BALB/c nude mice using optical coherence tomography. Journal of the Optical Society of Korea 2013; 17(1): 91-96, http://dx.doi.org/10.3807/josk.2013.17.1.091.

13. Skala M.C., Fontanella A., Hendargo H., Dewhirst M.W., Izatt J.A. Combined hyperspectral and spectral domain optical coherence tomography microscope for non-invasive hemodynamic imaging. Opt Lett 2009; 34(3): 289-291, http:// dx.doi.org/10.1364/ol.34.000289.

14. Leitgeb R., Hitzenberger C., Fercher A. Performance of fourier domain vs. time domain optical coherence tomography. Opt Express 2003; 11(8): 889-894, http://dx.doi.org/10.1364/ oe.11.000889. 
15. Gelikonov V.M., Gelikonov G.V., Shilyagin P.A. Linearwavenumber spectrometer for high-speed spectral-domain optical coherence tomography. Optics and Spectroscopy 2009; 106(3): 459-465, http://dx.doi.org/10.1134/ s0030400x09030242.

16. Gelikonov V.M., Gelikonov G.V., Kasatkina I.V., Terpelov D.A., Shilyagin P.A. Coherent noise compensation in spectral-domain optical coherence tomography. Optics and Spectroscopy 2009; 106(6): 895-900, http://dx.doi. org/10.1134/s0030400x09060174.

17. Gelikonov V.M., Gelikonov G.V., Terpelov D.A., Shabanov D.V., Shilyagin P.A. Suppression of image autocorrelation artefacts in spectral domain optical coherence tomography and multiwave digital holography. Quantum Electronics 2012; 42(5): 390, http://dx.doi.org/10.1070/ QE2012v042n05ABEH014852.

18. Shilyagin P.A., Gelikonov G.V., Gelikonov V.M., Moiseev A.A., Terpelov D.A. Achromatic registration of quadrature components of the optical spectrum in spectral domain optical coherence tomography. Quantum Electronics 2014; 44(7): 664, http://dx.doi.org/10.1070/ QE2014v044n07ABEH015465.

19. Gelikonov V.M., Gelikonov G.V. New approach to crosspolarized optical coherence tomography based on orthogonal arbitrarily polarized modes. Laser Phys Lett 2006; 3(9): 445451, http://dx.doi.org/10.1002/lapl.200610030.

20. Matveev L.A., Zaitsev V.Yu., Gelikonov G.V., Matveyev A.L., Moiseev A.A., Ksenofontov S.Yu., Gelikonov V.M., Sirotkina M.A., Gladkova N.D., Demidov V., Vitkin A. Hybrid M-mode-like OCT imaging of three-dimensional microvasculature in vivo using reference-free processing of complex valued B-scans. Opt Lett 2015; 40(7): 1472-1475, http://dx.doi.org/10.1364/ol.40.001472.

21. Li C.-Y., Shan S., Huang Q., Braun R.D., Lanzen J.,
Hu K., Lin P., Dewhirst M.W. Initial stages of tumor cell-induced angiogenesis: evaluation via skin window chambers in rodent models. J Nat Cancer Inst 2000; 92(2): 143-147, http://dx.doi. org/10.1093/jnci/92.2.143.

22. Prikaz Minzdravsotsrazvitiya RF ot 23.08.2010 №708n "Ob utverzhdenii Pravil laboratornoy praktiki" [Ministry of Health and Social Development of the Russian Federation Decree No.708n as of Aug 23, 2010 "On good laboratory practices of the Russian Federation"].

23. Mezhdunarodnye rekomendatsii (eticheskiy kodeks) po provedeniyu mediko-biologicheskikh issledovaniy $s$ ispol'zovaniem zhivotnykh [International guiding principles (ethical code) for biomedical research involving animals]. 1985.

24. Kiseleva E., Kirillin M., Feldchtein F., Vitkin A., Sergeeva E., Zagaynova E., Streltzova O., Shakhov B., Gubarkova E., Gladkova N. Differential diagnosis of human bladder mucosa pathologies in vivo with cross-polarization optical coherence tomography. Biomed Opt Express 2015; 6(4): 1464-1476; http://dx.doi.org/10.1364/BOE.6.001464.

25. Kirillin M.Yu., Farhat G., Sergeeva E.A., Kolios M.C., Vitkin A. Speckle statistics in OCT images: Monte Carlo simulations and experimental studies. Opt Lett 2014; 39(12): 3472-3475, http://dx.doi.org/10.1364/ol.39.003472.

26. Mariampillai A., Standish B.A., Moriyama E.H., Khurana M., Munce N.R., Leung M.K.K., Jiang J., Cable A., Wilson B.C., Vitkin I.A., Yang V.X.D. Speckle variance detection of microvasculature using swept-source optical coherence tomography. Opt Lett 2008; 33(13): 1530-1532, http://dx.doi. org/10.1364/ol.33.001530.

27. Mariampillai A., Leung M.K.K., Jarvi M., Standish B.A., Lee K., Wilson B.C., Vitkin A., Yang V.X.D. Optimized speckle variance OCT imaging of microvasculature. Opt Lett 2010; 35(8): 1257-1259, http://dx.doi.org/10.1364/ol.35.001257. 